Dom. Cien., ISSN: 2477-8818

Vol. 4, núm.4., oct, 2018, pp. 25-35

\title{
VPH y cáncer cervicouterino como un estigma social: un estudio desde el punto de vista psicosocial
}

\section{VPH and cervicouterino cancer as a social stigma: a study from the psychosocial point of view}

\section{VPH e câncer cervicouterino como estigma social: um estudo do ponto de vista psicossocial}

Leopoldo J. Gutierrez-Zambrano ${ }^{\mathrm{I}}$

leopoldo.gutierrezyahoo.com

María M. Cantos-Sánchez II

maria_12can@hotmail.com

Maristela E. Luzuriaga-Saltos ${ }^{\text {III }}$

maristela-luzu1@gmail.com
Araceli F. Venenaula-Orellana ${ }^{\text {IV }}$ araceli.f-133@gmail.com

Grace M. Montaño-Parrales V grace-montano@yahoo.com

Gema M. Loor-Vinueza ${ }^{\mathrm{VI}}$ gema.loor@gmail.com

Recibido: 27 de junio de 2018 * Corregido: 28 de agosto de 2018 * Aceptado: 15 de septiembre de 2018

I. Médico Cirujano, Hospital Verdi Cevallos Balda de Portoviejo, Portoviejo, Ecuador.

II. Enfermera Rural, Centro de Salud Guanazan Distrito 07D03, Portoviejo, Ecuador.

III. Médico Residente de Urología, Ministerio de Salud Pública; Hospital Pediátrico Baca Ortiz, Quito, Ecuador.

IV . Obstetriz, Centro de Salud Anegado Distrito 13D03 Jipijapa Puerto López, Ecuador.

v. Licenciada de Enfermería, Centro de Salud Jipijapa, Ecuador.

VI. Licenciada en Enfermería, Centro de Salud Ayacucho, Ayacucho, Ecuador. 


\section{Resumen}

En el siguiente trabajo se realizó un estudio desde el punto de vista psicosocial sobre VPH y cáncer cervicouterino como un estigma social. El virus de papiloma humano (VPH) pertenece a la subfamilia de virus papilomaviridae que afectan células superficiales de la epidermis y las mucosas, aunque pueden penetrar en las capas de la piel y multiplicarse. Esta infección tiene la consideración de ser la enfermedad de transmisión sexual más frecuente en el mundo. El diagnóstico de infección de VPH supone, en algunas mujeres, enfrentarse a una esfera llena de sentimientos encontrados. Los estudios sugieren también que los VPH pueden desempeñar un papel en los cánceres de ano, vulva, vagina y pene. Este tipo de cáncer se relaciona con las condiciones de pobreza y es el tercero más común entre las mujeres. Entre los resultados se obtuvo que las enfermedades de transmisión sexual (ETS) siguen creando, actualmente, un estigma social debido a la gran desinformación que las rodea. Dentro de ellas, la infección por VPH es la ETS más frecuente y, por tanto, la que más se diagnostica desde las consultas de ginecología. Cuando se explica el diagnóstico, vía de transmisión y patogenia de esta infección a una paciente, ésta suele acoger reacciones emocionales tales como culpa, vergüenza, miedo ó rechazo. A veces, el impacto emocional sufrido por dicho diagnóstico podría hacer hasta más daño que los síntomas clínicos causados por el virus. Se concluyó que los efectos del VPH, a diferencia de los observados en salud sexual, se encuentran más allá de la dimensión biológica. Padecer VPH, en particular para las mujeres, es causa de señalamiento y rechazo.

Palabras claves: Estigma, VPH, cáncer, vergüenza y ginecología. 


\begin{abstract}
In the following work, a psychosocial study on HPV and cervical cancer was carried out as a social stigma. The human papillomavirus (HPV) belongs to the subfamily of papillomaviridae viruses that affect superficial cells of the epidermis and mucous membranes, although they can penetrate the layers of the skin and multiply. This infection is considered to be the most frequent sexually transmitted disease in the world. The diagnosis of HPV infection involves, in some women, facing a sphere full of mixed feelings. Studies also suggest that HPV may play a role in cancers of the anus, vulva, vagina and penis. This type of cancer is related to the conditions of poverty and is the third most common among women. Among the results was that sexually transmitted diseases (STDs) continue to create a social stigma due to the great disinformation that surrounds them. Among them, HPV infection is the most frequent STD and, therefore, the most diagnosed since gynecological consultations. When the diagnosis, transmission route and pathogenesis of this infection is explained to a patient, it usually receives emotional reactions such as guilt, shame, fear or rejection. Sometimes, the emotional impact suffered by such a diagnosis could do even more harm than the clinical symptoms caused by the virus. It was concluded that the effects of HPV, unlike those observed in sexual health, are beyond the biological dimension. Having HPV, in particular for women, is cause for pointing and rejection.
\end{abstract}

Key words: Stigma, HPV, cancer, shame and gynecology. 


\section{Introducción.}

El virus de papiloma humano (VPH) pertenece a la subfamilia de virus papilomaviridae que afectan células superficiales de la epidermis y las mucosas, aunque pueden penetrar en las capas de la piel y multiplicarse. Hay aproximadamente 100 tipos de VPH, de los cuales 30 o 40 infectan el tracto genital, divididos en grupos de alto y bajo riesgo oncogénico. La infección clínica se hace visible por la aparición de condilomas, y puede continuar la aparición de displasias cervicales que constituyen lesiones premalignas de las células del cuello uterino, divididas en leve, moderada o severa (Gómez \& Peña, 2016)

La infección por virus del papiloma humano (VPH) tiene la consideración de ser la enfermedad de transmisión sexual más frecuente en el mundo. Su interés radica en que algunos tipos de VPH son de alto riesgo oncogénico, principalmente los serotipos 16 y 18. La prevalencia de infección por VPH en mujeres es relativamente alta, principalmente en mujeres jóvenes (hasta un 70\%). El diagnóstico de infección de VPH supone, en algunas mujeres, enfrentarse a una esfera llena de sentimientos encontrados. (Esquivel, Balmaseda, \& Portes, 2016)

Las infecciones persistentes por VPH se consideran ahora como la causa principal de cáncer cervical. En 2007, aproximadamente 11000 mujeres en Estados Unidos fueron diagnosticadas con este tipo de cáncer y aproximadamente 4000 habrían muerto a causa del mismo. Anualmente, el cáncer cervical afecta a cerca de medio millón de mujeres en el mundo y cobra 250000 vidas. Los estudios sugieren también que los VPH pueden desempeñar un papel en los cánceres de ano, vulva, vagina y pene. (García M. , 2010)

Este tipo de cáncer se relaciona con las condiciones de pobreza y es el tercero más común entre las mujeres. El proceso de salud, enfermedad y atención hace referencia a los saberes y 
significados socialmente compartidos sobre los padecimientos y las formas de atenderlos y erradicarlos. Los daños a la salud se comprenden como hechos sociales, de carácter histórico, que configuran representaciones y prácticas alrededor de los distintos saberes médicos (por ejemplo, el saber biomédico y el saber popular) y la forma de controlar e intervenir sobre los padecimientos. Una de las estrategias de control es la estigmatización de comportamientos relacionados con la presencia de ciertos padecimientos. En ese sentido, los significados atribuidos a las ITS se encuentran cargados de elementos estigmatizantes de la sexualidad, sobre todo en las sociedades occidentales y con prácticas católicas (Arellano \& Castro, 2013)

Algunos de los factores de riesgo para ser infectado de VPH son el inicio de la vida sexual activa a edades tempranas, múltiples parejas sexuales, historial de ITS, verrugas genitales, que la pareja sexual tenga cáncer de cervix o pene, multiparidad, tabaquismo, bajo nivel socioeconómico y/o de estudios; pobreza; drogadicción, la existencia de enfermedades que deprimen el sistema inmunológico, mala alimentación, higiene inadecuada, uso de anticonceptivos orales. Si bien un número mayor de parejas sexuales está fuertemente relacionado con las infecciones de transmisión sexual, esto se debe a la probabilidad mayor de entrar en contacto con un agente infeccioso. (Gómez \& Peña, 2016)

Una de las primeras propuestas teóricas sobre el estigma fue la de Benjamin Paul en los cincuenta, quien propuso que las personas con comportamientos en contra del orden social distinto al considerado normal, son estigmatizadas porque sus conductas cuestionan la moral y el apoyo social. El estigma tiene la finalidad de mantener el control sobre personas que no son consideradas normales o que no siguen ciertas normas definidas por los grupos dominantes, reproduciendo las distintas desigualdades basadas en el género, raza, clase, etnicidad y preferencia sexual. Otros 
trabajos muestran los distintos abordajes teóricos para analizar el estigma e identifican que las diferencias de poder social, cultural, económico y político delimitan lo que se define como estigmatizante. (Arellano \& Castro, 2013)

\section{Materiales y Métodos.}

En el siguiente trabajo académico se recurrió al método de la investigación documental. Esta herramienta metodológica se fundamenta en la recolección de documentos, categorizarlos, analizarlos; para después poder presentar un resultado coherente. El gran objetivo de este método es poder aportar nuevos conocimientos sobre el objeto de estudio. (Rodríguez, 2013)

También se puede decir que esta estrategia se basa en la observación y reflexión sistemática de realidades teóricas y empíricas, en la que usa diversos tipos de documentos que sirven para indagar, interpretar, exponer cifras e informaciones referentes al tema de ciencia que se trabaje. Todo utilizando instrumentos que tienen como meta conseguir resultados que pueden ser la plataforma para otra exploración científica más profunda o la construcción de nuevos conocimientos. (García \& Heras, 1994)

Se puede especificar en los siguientes pasos: realizar un proceso de abstracción científica, generalizando sobre la base de lo fundamental; utilizar los procedimientos lógicos y mentales de toda investigación; tales como: análisis, síntesis, deducción, inducción, entre otros; y se debe a una recopilación adecuada de datos, que permiten redescubrir hechos, sugerir problemas, ubicar hacia otras fuentes de investigación, orientar formas para elaborar instrumentos de investigación y elaborar hipótesis (Sampieri, 1998) 
Dicho trabajo se respaldó con una investigación bibliográfica que permitió abstenerse de elaborar exploraciones anteriormente realizadas, nutrirse del conocimiento de experimentos previos para emularlos en caso de ser necesario, buscar datos sugerentes, culminar investigaciones interrumpidas, seleccionar los materiales y documentos para realizar un marco teórico. (Bravo, 1999)

Con lo explicado anteriormente se puede aseverar que en el presente trabajo de investigación se utilizó como metodología una revisión bibliográfica documental no experimental. Con esta herramienta metodológica se realizó una revisión y análisis de diferentes artículos médicos y de opinión referentes al VPH y el cáncer cervicouterino como un estigma social, desde el punto de vista psicosocial.

\section{Resultados.}

Las enfermedades de transmisión sexual (ETS) siguen creando, actualmente, un estigma social debido a la gran desinformación que las rodea. Dentro de ellas, la infección por VPH es la ETS más frecuente y, por tanto, la que más se diagnostica desde las consultas de ginecología. Cuando se explica el diagnóstico, vía de transmisión y patogenia de esta infección a una paciente, ésta suele acoger reacciones emocionales tales como culpa, vergüenza, miedo ó rechazo. A veces, el impacto emocional sufrido por dicho diagnóstico podría hacer hasta más daño que los síntomas clínicos causados por el virus. (Esquivel, Balmaseda, \& Portes, 2016)

La mayor parte de las mujeres no ha vivido un rechazo abierto y evidente por la enfermedad, es el proceso de estigma interno que se traduce en autorecriminación y autocensura. Expresan vivencias cargadas de contenido simbólico sobre el ejercicio de la sexualidad propia y de la pareja lo que genera un silencio, un temor a compartir con otros la información, pues ello se percibe como

\footnotetext{
31 Vol. 4, núm. 4, octubre 2018, pp. 25-35

Leopoldo J. Gutierrez-Zambrano; María M. Cantos-Sánchez; Maristela E. Luzuriaga-Saltos; Araceli F. Venenaula-Orellana; Grace M. Montaño-Parrales; Gema M. Loor-Vinueza
} 
una amenaza a su integridad personal y a la construcción social sobre la feminidad y la sexualidad. (Arellano \& Castro, 2013)

Existen redes de apoyo social las cuáles son una práctica simbólica-cultural que incluye el conjunto de relaciones interpersonales que integran a una persona con su entorno social y le permiten mantener o mejorar su bienestar material, físico y emocional y evitar así el deterioro real o imaginario que podría generarse cuando se producen dificultades, crisis o conflictos que afectan al sujeto. Los estudios concluyen que el apoyo social es un elemento importante en la salud de las personas, aunque en ocasiones puede ser contraproducente en enfermedades que conllevan estigma y descrédito social; tal es el caso de la condena social por padecer una infección de transmisión sexual (ITS) que interfiere en la búsqueda de apoyo en las redes. (Castro \& Arellano, 2014)

\section{Conclusiones.}

Los efectos del VPH, a diferencia de los observados en salud sexual, se encuentran más allá de la dimensión biológica. Padecer VPH, en particular para las mujeres, es causa de señalamiento y rechazo. Al respecto, se ha encontrado que el estigma hacia las mujeres con VPH en la mayoría de las ocasiones no se debe a un rechazo abierto en la interacción social, sino a un proceso interno que genera autodiscriminación y autocensura en ellas mismas. (Palacios, Méndez, Galaza, \& Torres, 2016)

Hemos mostrado con los testimonios que cada diagnóstico tiene significados distintos en la percepción individual y en el imaginario social del grupo de pertenencia, que lleva a las mujeres a una vivencia que puede estar cargada de incertidumbre y angustia. La perspectiva de género nos brinda elementos para analizar las decisiones y gestiones de las mujeres, comprendiendo su posición en un medio social que enjuicia la sexualidad, sobre todo la femenina. (Castro \& Arellano, 2014)

\footnotetext{
32 Vol. 4, núm. 4, octubre 2018, pp. 25-35 
Las mujeres que cuentan con redes sociales informales sólidas pudieron enfrentar su proceso de atención con menor costo económico, pero también con menos angustia e incertidumbre, ya que las redes les proporcionan apoyo emocional e instrumental, el contar con estas redes les permite mantener cierto bienestar y evitar un deterioro físico, emocional y económico mayor ante una situación difícil como es una enfermedad. (Castro \& Arellano, 2014)

Las participantes en el estudio prefieren no socializar sus diagnósticos y si lo hacen, es de manera muy limitada; tratan de evitar las relaciones sexuales, comparten sus diagnósticos solo entre sus redes de mayor confianza y con mucha secrecía, se aíslan de sus redes familiares y sociales, abandonan sus actividades laborales y educativas como acciones protectoras frente al estigma interno afectando su proceso de s/e/a. Resulta importante desenredar estos procesos subjetivos e internos de estigmatización para comprender las decisiones en salud que toman las mujeres durante sus trayectorias y los mecanismos para ejercer su derecho a la atención a la salud, pero también para poner en la mesa de discusión de la atención ofrecida en las instituciones de salud (Arellano \& Castro, 2013)

\section{Recomendaciones.}

En lo que se refiere a la prevención del VPH, es importante generar acciones basadas en enfoques con una visión promocional de la salud sexual y una perspectiva de género. (Palacios, Méndez, Galaza, \& Torres, 2016)

El trabajo aporta elementos para el análisis de los procesos microsociológicos, cuya finalidad sea el diseño de programas de prevención, atención y tratamiento, así como en la implementación de políticas públicas enfocadas en las necesidades de las comunidades de estudio (Arellano \& Castro, 2013)

33 Vol. 4, núm. 4, octubre 2018, pp. 25-35

Leopoldo J. Gutierrez-Zambrano; María M. Cantos-Sánchez; Maristela E. Luzuriaga-Saltos; Araceli F. Venenaula-Orellana; Grace M. Montaño-Parrales; Gema M. Loor-Vinueza 
Como médicos debemos apoyar a la paciente a enfrentarse a la enfermedad también en la esfera psicológica. Brindarle la información que requiera, aclarar dudas e, incluso, ofrecer la posibilidad de visita en consulta otro día para continuar el proceso de asimilación de información; estos deben ser nuestro dogmas a seguir (Esquivel, Balmaseda, \& Portes, 2016)

\section{Bibliografía.}

Arellano, M., \& Castro, M. (2013). El estigma en mujeres diagnosticadas con VPH, displasia y cáncer cervicouterino en Hermosillo, Sonora. Estudios Sociales, 263-275.

Bravo, S. (1999). Tesis doctorales y trabajos de investigación científica : metodología general de su elaboración y documentación. Madrid: Paraninfo.

Castro, M., \& Arellano, M. (2014). Redes sociales de apoyo y género: vivencia de mujeres con VPH, displasias y cáncer cervicouterino. La ventana. Revista de estudios de género, 208240.

Esquivel, J., Balmaseda, E., \& Portes, M. (2016). Impacto emocional tras diagnóstico de infección por. UGC de Obstetricia y Ginecología, 1.

García, E., \& Heras, C. (1994). Metodologia de la investigación. Buenos Aires: Nueva Librería.

García, M. (2010). VPH y cáncer de cuello uterino. Salus, 5-6.

Gómez, D., \& Peña, E. (2016). La vivencia del VPH en la Ciudad de México. Experiencias de investigación en salud desde la perspectiva antropológica, 1-23.

Palacios, O., Méndez, S., Galaza, D., \& Torres, T. (2016). Dominios culturales de Salud Sexual y Virus del Papiloma Humano en adolescentes mexicanos. CES Psicología, 152-166. 
VPH y cáncer cervicouterino como un estigma social: un estudio desde el punto de vista psicosocial

Rodríguez, S. (2013). Acerca de la investigación bibliógrafica y documental. Obtenido de Guia de

Tesis: http://guiadetesis. wordpress. com/2013/08/19/acerca-de-la-investigacion-

bibliografica-ydocumental

Sampieri, R. (1998). Metodologia de la Investigación. Mexico DF: Interamericana editores. 